\title{
«Roundabout I-V/» de Martín Gubbins o dos lecturas de lo
} ilegible

\section{«Roundabout I-V/» by Martín Gubbins or Two Approaches towards IIlegi- bility}

Alethia Alfonso ${ }^{1}$

Universidad Iberoamericana, Ciudad de México, México

\section{RESUMEN}

En este artículo planteo la relación que existe entre algunos postulados de Eric Mottram, uno de los iniciadores de British Poetry Revival, con la poesía de Martín Gubbins. Abogo por abrir las posibilidades de influencia anglosajona más allá de los conocidos Ezra Pound y William Carlos Williams. Además, busco entender qué sucede con el sujeto en poéticas contemporáneas predominantemente visuales y performativas. Por último, esbozo una noción de la relación que poemas como «Roundabout $|-V|$ » de Gubbins tienen con la (in)estética según Alain Badiou.

\section{PALABRAS CLAVE}

Poesía latinoamericana, British Poetry Revival, experiencia poética, materialidad, performance, notación

\section{ABSTRACT}

This article deals with the relationship between some statements written by Eric Mottram, one of the founders of the British Poetry Revival, and Martín Gubbins' poetry. I advocate for opening towards English influences which are not the usual poets, namely Ezra Pound and William Carlos Williams. Another aim is the understanding of the role of the subject in contemporary poetics - which are predonminantly visual and performatic experiences. Lastly I deal

\footnotetext{
1 Estudió la licenciatura en Literatura Latinoamericana en la Universidad Iberoamericana. Realizó estudios de doctorado en el Birkbeck College, University of London. Es docente y coordinadora del Posgrado en Letras Modernas. Ha publicado artículos sobre poesía y artes visuales contemporáneas en el Perú, Chile y España.
} 
with the relationship between poems like «Roundabout $|-V| »$ by Gubbins and Alain Badiou's ideas of (in)aesthetics.

\section{KEYWORDS}

Latin American poetry, British Poetry Revival, poetic experience, materiality, performance, notation

Uno de los retos que enfrento ante la crítica latinoamericana respecto a la poesía contemporánea es tratar de indagar sobre las influencias de los poetas nacidos después de 1960. Basta decir que, al menos en México, gran parte de los colegas sigue pensando en las influencias dicotómicas francesas y norteamericanas, o en el binomio influencia nacional e internacional. Por francesas me refiero a que continúan pensando en Baudelaire y Rimbaud; mientras que para la influencia norteamericana se sigue citando a Pound y Williams. Si bien estos poetas han sido una influencia notable para la poesía contemporánea, considero oportuno voltear hacia otras latitudes y a fenómenos de la segunda mitad del siglo XX, que también se alimentaron de este cuarteto maravilla y han acuñado una poética propia, que a su vez ha tenido consecuencias en poéticas cercanas a nosotros, como la poesía chilena contemporánea.

Para intentar mostrar otras vías de acercamiento con los textos latinoamericanos, analizo en este artículo específicamente los poemas «Roundabout I-V|» de Martín Gubbins (Chile, 1971), publicados en London Poems (2001-2003), la influencia que el legado de Eric Mottram y Bob Cobbing tienen en estos poemas, y las consecuencias para los estudios literarios contemporáneos, en particular para mi investigación sobre el arte, de acuerdo con algunos postulados de Alain Badiou.

\section{Mottram, Cobbing, Gubbins}

Eric Mottram y Bob Cobbing formaron parte de un grupo conocido en los 70 como el British Poetry Revival. Su mención y estudio es pertinente porque Mottram fue quien encabezó en ese tiempo el estudio de la poesía contemporánea norteamericana (estadounidense y canadiense) en los estudios literarios de habla inglesa. Gracias al interés de Mottram y su grupo, poetas como Pound, Williams, los Beats y posteriormente los $\mathrm{L}=\mathrm{A}=\mathrm{N}=\mathrm{G}=\mathrm{U}=\mathrm{A}=\mathrm{G}=\mathrm{E}$, fueron conocidos y leídos en latitudes británicas. A Cobbing, por su parte, se le atribuye haber fundado en 1963 el Writers Forum (WF), un foro tipo taller y network donde se acuñaron poéticas -o experiencias poéticas, si seguimos los postulados de Mottram-como la de Bill Griffiths, Allen Fisher, Sean Bonney, Maggie O'Sullivan, entre otros. El WF tuvo réplicas fuera de Londres, incluida la fundada por Martín Gubbins en Chile. 
La réplica chilena se llamaba el Foro de Escritores (FDE) y tenía, entre otros exponentes, a Martín Gubbins, Felipe Cussen, Andrés Anwandter y Kurt Folch. El grupo se reunía, leía, creaba y autoeditaba — no estoy del todo segura que lo siga haciendo- bajo el nombre de FDE. Cabe mencionar que el poco tiempo que pude convivir con los autores del FDE noté que, aun cuando tenía influencias diversas y poéticas diferentes -las cuales iban desde la reconsideración de las formas poéticas clásicas hasta el uso de instrumentos musicales, juguetes y materiales cotidianos para crear experiencias sonoras - , el grupo entendía la poesía como un frente común, contra quienes veían en la poesía chilena a Gabriela Mistral y Pablo Neruda como referentes únicos. De ahí que parte de la labor del FDE era considerar otras poéticas, otras latitudes. La labor de Gubbins, Cussen y compañía era similar a la labor pedagógica emprendida por los concretistas brasileños, los hermanos de Campos y Décio Pignatari. Contrario a estos últimos, sin embargo, los de FDE no publicaban con miras a educar al público, más bien compartían autores y poéticas ${ }^{2}$ entre sí. La inoculación de virus poético, por llamarlo de algún modo, llegaría con los performances, la poesía sonora y la visual con que se dieron a conocer en Chile, Reino Unido, México y Estados Unidos.

\section{El diseño en la experiencia poética}

Aparte de llevar consigo la réplica de taller, lectura, edición y networking del WF, Gubbins atrajo la atención a dos de los retos con los que se lidia desde la época del British Poetry Revival: entender el texto poético más como «the publication of the poetic experience [which] usually involves choice of notation [...and also that] the design of poetry occurs as an interface between notation and performance» (Mottram, 2004, p. 9). Es decir, Mottram argumenta que aquello que entendemos coloquialmente como poema publicado no constituiría poesía, a partir de la cual los lectores tendrían experiencias estéticas, fundamentadas en su mayor parte en la creación de imágenes, sonoridades e ideas con un trabajo cuidadoso de un lenguaje pensado como base inamovible. No lo haría, no porque los poetas que sigan los postulados de Mottram fuesen incapaces de trabajar el lenguaje, sino porque la relevancia de la experiencia poética yacería en la habilidad del autor en demostrar posibilidades poéticas ajenas —en la medida de lo posible - a las opciones ya conocidas de consumo. Fuera de la experiencia poética à la Mottram quedarían los premios nacionales de poesía, los concursos de juegos florales, los de editoriales para publicación,

2 En este sentido, parte de la labor del Foro de Escritores consistía en un taller, similar para mí al de Hugo Gola en México, bajo el cobijo de las revistas de poesía que tuvo a su mando, y que terminó con el regreso de Gola a Argentina y su posterior muerte. 
e incluso quienes buscan insertarse en una tradición poética con fórmulas conocidas; ejemplo de ello en Latinoamérica serían los poetas que intentan en pleno siglo XXI unir símbolos y tropos pensados como locales con aquellos universales, aunque en realidad estos últimos sean grecorromanos o judeocristianos.

Ahora bien, el interés de Mottram y del British Poetry Revival de ir más allá de las opciones de consumo poético buscaba tres objetivos - que yo haya detectado-: (1) recolocar la poesía en un lugar que produzca catarsis y una experiencia fenomenológica novedosa-, es decir, que provocase una reacción o un cambio mínimo o una percepción distinta del lector-espectador, a través de su experiencia estética-; (2) considerar que la experiencia poética contemporánea demanda un acercamiento al diseño, entendido a veces como interacción entre acción performativa y notación o partitura textual — piénsese en la poesía concreta-y otra veces como un tratamiento permanente, realizada por el poeta desde que escribe o piensa, enuncia o publica ${ }^{3}$; (3) también buscaba darle sentido a la libertad que el uso y el trabajo con la materialidad permitía entre los poetas. La materialidad en la poesía permitiría que [casi] cualquier experiencia fuese susceptible de crear una experiencia poética, siempre y cuando se haya trabajo con la materialidad - que puede o no ser lenguaje-, con la interacción entre la notación y el performance, y que culmine con una experiencia. El programa planteado por Mottram incluye además a los poetas anteriores; esto es, aun cuando la acuñación de la experiencia poética resultase novedosísima, esta no soslaya los referentes anteriores y contemporáneos. Baste saber que Sean Bonney del WF actual tiene reflexiones y poemas a partir de figuras como Baudelaire, y Martín Gubbins ha retomado a Blake, los concretistas brasileños y a Pound, porque el grupo no descarta la influencia y el legado poético con el que cada cual se identifica. No obstante, sí cuestiona la manera en que la experiencia poética llega al lector-espectador.

\section{«Roundoubt I-VI»}

La lección para los poetas contemporáneos entreteje más una red de posibilidades que de cláusulas obligatorias para hacer poesía. Martín Gubbins, el WF y el FDE recuperan esa opción de posibilidades para su ejercicio creativo. Concretamente en London Poems (2001-2003), del que se desprende la serie «Roundabout I al Vl», hay un ejercicio de posibilidades

3 Hay una cita de Bob Cobbing en el texto de Mottram que enfatiza: «all poems are treated poems. Even a found poem inevitably undergoes treatment before it can be circulated in an edition» (Mottram, 2007, p. 43). 
y una notación (notation) con potencial de ejecución en performance que también se traduce como una sucesión textual, que apunta a la acuñación de una experiencia poética. «Roundabout I-V|» debe tratarse como serie por un motivo fundamental: en «Time and Visual Poetry», publicado en el número 3 de Pores: A Journal of Poetics Research, Gubbins argumenta que el tiempo «becomes an important element of my practice as a poet [particularly] representation of time, time and structure, and time and performance» (2003) $)^{4}$. Una de las posibilidades para aprehender el texto como experiencia temporal es a través de la seriación del trabajo poético en textos que tiene una forma particular y apuntan a un fenómeno conocido por todos los que transitamos en la ciudad: las rotondas o glorietas, en inglés roundabout, como la famosa canción de Yes (1976).

«Roundabout» emula un diagrama bidimensional de las glorietas con cuatro brazos o salidas para el transporte. En las primeras tres series, las líneas perimetrales de los brazos y el área del centro de la rotonda están hechos de grafías - que en un acercamiento consisten en palabras en inglés que se repiten y se relacionan con las posibles sensaciones e ideas en torno a la glorieta. El léxico se repite sin espacio entre palabras y con diversas formas de lectura (de izquierda a derecha y viceversa, con las grafías en posición tradicional de lectura y en espejo, de abajo arriba y viceversa). En las primeras series se lee: «curbednessboundednesslimitedness» («Roundabout I, II, III»), en blanco sobre fondo blanco y fuentes en negro, en blanco sobre fondo negro con fuentes en gris claro para los brazos y negro para el centro, y en negro sobre fondo negro, con fuentes en blanco. Parecería que las tres palabras se relacionan con las limitaciones propias de la experiencia de estar una rotonda. El sufijo -ness se emplea para crear sustantivos. Es notable que los sustantivos se formen a partir de los participios del verbo, es decir, el sustantivo parte de las acciones y se aleja así de una abstracción que provenga de una subjetividad; esto es, de la acción realizada por un sujeto. Limitedness es el sustantivo de limitado, boundedness es el sustantivo de encerrado, y curbedness, de controlado.

Las otras tres series emplean grafías de palabras en inglés para llenar la superficie de la rotonda, dejando el círculo central como un espacio vacío. En ellos se lee sin espacios entre palabras: «breaklessnesslesnesslessnessendlessness» «endlessnesslessnessstoplessness»

4 Existe en Birkbeck College una tesis sobre temporalidad, tiempo y poesía del British Poetry Revival escrita por Stephen Mooney. Dado que el tiempo no será problematizado en este artículo, remito a los lectores a la tesis doctoral de Mooney si buscan ahondar en el tema. 
"ceaselessnesslessnessbreaklessness», con el sufijo -lessness repetido entre una palabra y otra ( Roundabout IV, V, VI»), en un fondo blanco sobre blanco con fuente color negro, en fondo negro con fuente blanca y finalmente en fondo blanco sobre blanco con una fuente fuera de foco que impide la legibilidad rápida y usual.

Si en las primeras tres series los sustantivos parten de verboides, en las tres restantes los sustantivos tienen como origen adjetivos negativos, que se traducirían como «irrompible, interminable, imparable e incesante», reforzados por la repetición del sufijo -lessness. Es también notorio que desde la serie IV a la VI, la legibilidad se vuelve más difícil. Primero, porque las letras están superpuestas; después, porque en la última serie las palabras se duplican y están desfasadas unos milímetros, por lo que adquieren la ilusión óptica de estar fuera de foco o mal impresas.

Las características anteriores ejemplifican la problematización que plantea Gubbins en su artículo para Pores. Por un lado, la representación del tiempo, en tanto una de las características ataduras de quien vive en la rutina, y cómo esta "determine how we live» (Gubbins, 2003), puede entreverse en la elección semántica: los sustantivos están orientados a un campo semántico de encierro en las primeras series y luego de repetición incesante en el último tercio. Mientras que la ilegibilidad de los últimos textos pudiera entenderse como una posibilidad de liberarse. El costo sin embargo no es bajo: sin legibilidad, las grafías y por tanto la semántica pierden estabilidad durante la lectura (es decir, durante el movimiento de ojos de lector). Al perder estabilidad, el resquicio de libertad se deja ver solo gracias a la imposibilidad de lectura y por tanto de creación de sentido.

Por otro lado, Gubbins une tiempo y estructura con el ritmo. Si bien alude a Pound y a los poetas brasileños, Gubbins determina que su atención hacia el ritmo es más visual que métrica versificada, por eso argumenta que se concentra más en crear una forma irrepetible, cuyo diseño sirva como base visual estructural y por tanto rítmica (en tanto creación de patrones que den sentido a lo que se ve y lee). En este caso, la forma de rotonda es empleada solamente en las series de textos denominados «Roundabout». Ciertamente, la materialidad de la serie intenta ser la rotonda misma. Quedaría por explorar si esto obedece a un afán conceptualista. Mi particular intuición se orienta más a pensar en Gubbins y en varios poetas del WF y del FDE como poetas (post-)fenomenológicos. Esto es, como autores que buscan crear experiencias poéticas que rayan en los límites de lo (no)sensible, y no quieren desplegar ingenio a través de alegorías conceptuales. El argumento anterior se refuerza con la idea que Gubbins lanza en el artículo mencionado; él dice que el tiempo y el performance (o ejecución) de los textos están relacionados porque los poemas 
con una fuerte carga visual pueden cambiar al momento de ser leídos, debido a que cuentan con un rango amplio en sus posibilidades de lectu$\mathrm{ra}$, que a su vez son modificadas por/con el tiempo. El performance o ejecución que acompañaría a «Roundabout I-V|» no tiene por qué incluir la misma cantidad de palabras, ni palabras del todo, ni los mismos patrones visuales traducidos a sonidos. Dicho de otro modo, «the poem becomes a creature uneasy to label» (Gubbins, 2003). Lejos de hacer problemática la lectura, permite una suerte de gemación, si se permite el término biológico, dado que el poema visual y el posible performance o la versión sonora no necesitarían contener el núcleo original, siempre y cuando ofrecieran una experiencia poética.

Para este momento, resulta claro que Gubbins retomaría de Mottram y del WF las ideas sobre la materialidad, la creación de una experiencia poética alejada de las maneras habituales de consumir poesía, la necesidad de entender el texto publicado como notación o partitura -y no como un texto único con una sola forma correcta de leerse-, la noción de diseño como interacción entre performance y notación, así como la asunción de todo poema como un poema tratado (treated poem). Por eso «Roundabout I-V|» muestra un amplio registro en el uso de la materialidad, al punto de llegar a la ilegibilidad-que podría constituir una experiencia poética renovadora. Aunque falta el elemento performativo para redondear la idea, considero la serie de poemas como una notación que interactuaría con el performance, al grado de modificar o tratar el poema, dadas las consideraciones que Gubbins plantea en «Time and Visual Poetry».

El resultado entonces resaltaría que las ideas de Mottram son vigentes, al menos para los textos poéticos aquí tratados. Sin embargo, el artículo no termina en análisis y síntesis; si bien la influencia de Mottram (a través del WF) en Gubbins es mayúscula, existen características propias de la poética de Gubbins que apostarían a modificar elementos considerados vitales en la poesía. Trato dos únicamente: el sujeto poético y la noción que Badiou postula de arte.

\section{El ineludible sujeto}

En «Roundabout I-V|» como en otros poemas contemporáneos parece no existir un sujeto que enuncia. El lector nota que no hay un sujeto o una voz, y tampoco parecen existir sujetos en quienes recaen las acciones. $\mathrm{Si}$ se recuerda bien, el vocabulario en las serie de poemas se limita a campos semánticos de sustantivos relacionados con la experiencia de transitar en una rotonda. No hay, sin embargo, un sujeto ni voz que transite. Hasta este punto, podríamos argumentar que Gubbins crea poemas sin sujetos y sin voz poética. Pero (siempre habrá un pero) él y otros del WF y del FDE no 
obliteran, sino desplazan al sujeto y la voz enunciantes hacia el sujeto o los sujetos y voces que ejecutan las lecturas o performance a partir de los poemas. Esto coincide con Mottram: si el poema impreso es considerado ahora la publicación de la experiencia poética, pero no la experiencia misma, esta última es lograda gracias a un sujeto que ejecuta un performance. $A$ reserva de encontrar alguna entrevista que me contradiga, sospecho que Gubbins no busca prescindir del sujeto poético; más bien traslada el foco de atención hacia un momento de espacio-tiempo en el cual la interacción entre el texto poético-partitura, el performance resultante y los sujetos en sus roles de enunciante (o poeta o performer) y espectador (o lector) es tan cercana que no hay cómo desentenderse de la experiencia poética. Exista o no la pequeña catarsis que menciona Mottram, hay una experiencia de la cual pueden dar testimonio los sujetos involucrados en sus respectivos roles.

¿Comprender que el sujeto no puede eliminarse de la poesía o de la experiencia poética demerita «Roundabout I-VI», a Mottram o a Gubbins? No. Permite, en todo caso, conocer mejor los alcances de los postulados del British Poetry Revival y de los poemas de Gubbins incluidos en London Poems (2001-2003). Mottram, Gubbins y compañía no buscan eliminar el sujeto, porque la base de la experiencia poética es fundamentalmente subjetiva y fenomenológica. La llamo fenomenológica porque Mottram asume que la capacidad del sujeto para tener experiencias que vive, analiza y asimila, a fin de dar sentido al mundo, a otras experiencias y a la vida cotidiana, es la espina dorsal para que ese sujeto en su rol lector y espectador experimente y entienda la experiencia poética. La llamo subjetiva porque tanto el autor como el lector y espectador necesitan asumirse como sujetos con roles específicos durante la interacción, para que esta culmine en una experiencia.

El problema con entender la poesía como experiencia que necesita del performance y la notación es la limitación espacio-temporal de la experiencia poética. Por un lado, es positiva porque terminaría con la creencia de la universalización del dicha experiencia. No por afán exclusivista, sino por mera practicidad: incluso con un sujeto que hipotéticamente ejecutara el performance de un poema cuando se le pidiera, la ejecución repetida al infinito tendría alteraciones según el cansancio y otras variables propias de lidiar con un sujeto vivo y, por tanto, cambiante. Por otro lado, la limitación es negativa porque los alcances catárticos quedarían disponibles solamente para quienes presenciaron el performance. Incluso el poema impreso o la publicación de la experiencia carecería de los elementos presentes en el momento de la ejecución. Ciertamente, quienes nos interesamos por la poesía atesoraríamos en la memoria los performances 
que presenciáramos. Pero la posibilidad de conocer otras experiencias, en otras latitudes e incluso en otras lenguas parecería tan limitada que correríamos el riesgo de caer en localismos: pensar que únicamente podemos criticar y analizar lo que pasa en nuestro contexto y tiempo. Justo uno de los retos presentes de la crítica latinoamericana es abandonar primeramente las dicotomías de lo nacional o local contra lo extranjero o global, porque en poesía las influencias son locales, extranjeras, contemporáneas e incluso pretéritas.

¿Cómo resolver el dilema? O en términos del artículo, ¿cómo argumentar que este artículo no es un análisis del detrito de la experiencia poética, a la cual no se tiene acceso? Echaría mano de la lecciones de filosofía posestructuralista: no rescataría el artículo, asumiría la pérdida. Retornar al origen es imposible; por lo tanto trabajaría a partir de las posibilidades que ofrece los materiales disponibles. Iría aún más allá y me atrevería a apoyar mi postura con algunos términos de Badiou.

\section{«Roundabout I-VI» y la relación entre arte y filosofía}

El primer capítulo del Handbook of Inaesthetics ofrece un panorama de la relación entre arte y filosofía, de acuerdo con Alain Badiou. Resumo entonces que el arte y la filosofía han mantenido relaciones didácticas, románticas y clásicas. En las didácticas el arte enseña algo que no es la verdad, porque esta existe fuera del arte, sino el efecto (incluso atractivo) de la verdad. La norma o regulación del arte proviene de la educación y la norma o regulación de la educación proviene de la filosofía (Badiou, 2004, p. 3). En las relaciones románticas, el arte es el cuerpo real de la verdad, no necesita de la filosofía porque el arte educa a través su asunción como encarnación del absoluto al cual la filosofía no puede aspirar (p. 3) $)^{5}$. En las relaciones clásicas, el arte no es ni encarna la verdad porque un tamiz mimético la exime de ser parte de lo real y de encarnar, por tanto, la verdad. El arte es verosímil y útil; y la filosofía, por su parte, puede vivir sin el arte.

Badiou busca desacreditar estos esquemas y proponer el propio. En él, postula que «art is a thought in which artworks are the Real (not the effect). [...] Immanence: Art is rigorously coextensive with the truths that it generates. Singularity: These truths are given nowhere else than in art» (p. 9). En palabras más llanas: el arte es considerado un pensamiento por sí mismo (contrario al esquema didáctico), los productos resultantes serían lo Real (es decir, no tendrían el tamiz mimético-verosímil ni el efecto catártico del esquema clásico) y sería inmanente en tanto correspondiera

5 Debo decir que en el recuento que hace Badiou se nota cierta mofa a otros filósofos como Jean-Luc Nancy. 
a las verdades que genera (esto es, sin los absolutos ni encarnaciones del esquema romántico). Por último, Badiou considera que las verdades del arte se dan solamente en el arte. Lo anterior parece redundante, pero si se considera que ha existido una instrumentalización del arte (piensen en el arte que busca mostrar las atrocidades contra los oprimidos, en quienes emplean el arte para demostrar teorías psicoanalíticas o en quienes aprecian el arte como ejemplos de moral), la tautología se elimina.

Resulta interesante pensar en «Roundabout I-VI» como una experiencia poética, susceptible a ser llamada producto artístico (artworks), debido a que el ejercicio consecuente sería entender por qué esa serie de poemas constituirían lo Real (sin mediaciones) para el arte como pensamiento. De entrada puedo argumentar qué es lo Real debido al uso de la materialidad y el interés por la experiencia (más cercana a lo Real). Sin embargo, fallo al argumentar que los postulados de Mottram serían el equivalente al arte como pensamiento, porque eso eliminaría lo Real. Me explico: lo Real es aquello que se experimenta (o se busca experimentar) libre de mediaciones lingüísticas, lógicas y analógicas. Por lo tanto, una serie de postulaciones sobre la poesía - por libre que fuese la concatenación de ideas - necesita del lenguaje y de otras estrategias de mediación para asentarse. No obstante, si se argumenta que Gubbins no pensaba mientras escribía o mientras ejecutase un performance, entonces cabría la posibilidad de hacer del performance y de la serie de poemas parte de lo Real, si el arte como pensamiento fuera su punto de partida hacia la acción. Aclaro, no es que Gubbins sea incapaz de pensar, sino que para fines de Badiou convendría entender que la inmersión del poeta en su trabajo es tal que no existen distractores y aquello que crea se experimenta como la única acción posible en ese momento del espacio-tiempo. Bajo estas condiciones, «Roundabout I-VI» es lo Real y no su efecto. Esto concuerda con la búsqueda de Mottram de una experiencia poética que se alejara del aprendizaje de vocabulario o del entretenimiento.

La inmanencia en el arte como rigurosamente correspondiente a las verdades que genera ayuda a afianzar cómo «Roundabout I-V|» busca romper esquemas, mostrar nuevas formas de hacer y ejecutar la experiencia poética, pero no intenta crear ni mostrar encarnaciones de absolutos. Esta serie de poemas no agota las rotondas. Ciertamente, tampoco busca poner en un pedestal nuevos conceptos absolutos sobre poesía, ni arte, ni belleza, ni placer, ni urbanismo. Al contrario, entiende que todo lo que genera - derive esto en experiencias poéticas o en construcciones de verdades - tiene un régimen local y existe en y solamente para los fines del mismo poema. Es interesante pensar que si el tiempo modificase este poema visual al grado de constituir otro objeto en su ejecución 
sonora (por gemación, decía anteriormente), como argumenta Gubbins, cambiaría potencialmente las verdades generadas; sería entonces otro producto artístico todavía ligado sin embargo al arte como pensamiento.

En cuanto a la singularidad y la noción de que las verdades del arte se dan en él y nada más, hay una colisión entre lo planteado por Mottram y lo expresado por Badiou, que necesariamente altera la posible lectura del poema de Gubbins. La razón detrás es que Mottram sí espera que la singularidad del arte que él plantea sacuda (recuérdese que se refiere a la catarsis) al espectador o lector, a fin de que este conozca otras experiencias fuera de la esfera de consumo. Quizá una forma de salvarlo sería que el arte como se plantea en el sistema filosófico de Badiou apuesta por volverse un acontecimiento. Como tal, el sacudimiento que espera Mottram dejaría der ser parte de un esquema didáctico para convertirse en una característica necesaria de un acontecimiento que sacude los cimientos del sujeto ${ }^{6}$. O tal vez el mismo Badiou logra independizar al arte de la filosofía — de ahí que emplee el término inestética en lugar de estética-, pero no logre salvar al arte de cierto dejo aleccionador. Quizá, por otro lado, no haya salvación, sino un ejercicio constante que intenta probar los alcances de sistema de pensamiento frente a un sistema de ejecución poética.

\section{Conclusiones}

Las maneras de leer y acercarse a poemas cercanos a la ilegibilidad son varios. En este artículo apenas había tres acercamientos: el histórico con Mottram como cabeza de un movimiento poético que repercutió en el grupo del cual Gubbins formó parte; el analítico descriptivo, cuyo objetivo era encontrar las formas en las que los postulados de Mottram y el contexto de Gubbins se mezclaban; y por último un primer acercamiento a las posibilidades de cuestionamiento con algunos conceptos como el sujeto y las nociones introductorias de arte para Badiou. La brecha abierta es clara: se puede analizar la poesía latinoamericana sin las influencias de los poetas anglosajones clásicos y alejándonos de las dicotomías usuales.

También hay límites para el artículo. Entre ellos, considero que el uso del vocablo diseño para referirse a los postulados de Mottram tendría que modificarse, porque la palabra ha quedado corta para los alcances que los WF y los FDE han logrado con sus poemas y performances. Han logrado ir más allá de la interacción entre notación y ejecución, logran cuestionar la asimilación de la experiencia con textos y performances que se resisten a

6 Debo aclarar que la noción de sujeto de Badiou no es precisamente la de un sujeto individual. 
interpretaciones y/o acercamientos sensitivos (eso que llamaba en párrafos anteriores posfenomenológicos).

Una segunda limitación, asumida páginas antes, es el performance desconocido (para mí, al menos) de «Roundabout I-V|» a fin de crear y postular una idea más redondeada de la experiencia poética. Una tercera y última limitación es el entendimiento a un sistema filosófico compatible con pocos fenómenos poéticos concretos. De hecho, Badiou utiliza como ejemplo para reafirmar su posición frente al arte el poema del fauno de Mallarmé. De modo que, sí, la osadía de buscar vínculos con poéticas como las de Gubbins requiere todavía más investigación y meditación. Termino el artículo con lo siguiente: es importante entender que realzar la influencia británica se relaciona menos con un afán neocolonialista que con una petición académica de comenzar a entender que los poetas toman influencias de donde su voluntad, contexto y necesidades requieran, sin importar la mayor parte de las ocasiones si la influencia en cuestión es moderna, antimoderna, colonialista, anticolonialista, nacionalista o de otra índole. Comprendo que, como aspirante a crítica, no puedo soslayar semejantes adjetivos; sin embargo, puedo y debo evitar que estos pesen más que los argumentos y el análisis poético, dado que unos y otros ayudarían a colocar tal influencias política o ideológicamente problemáticas en su lugar. 


\section{REFERENCIAS BIBLIOGRÁFICAS}

Badiou, A. (2005). Handbook of Inaesthetics. Stanford: Stanford University Press.

Mottram, E. (1977/ 2004). Towards Design in Poetry. Londres: Veer BooksWriters Forum.

Gubbins, M. (2003). Time and Visual Poetry. Pores: A Journal of Poetic Research. 3. Recuperado de http://www.pores.bbk.ac.uk/3/gubbins.html.

Gubbins, M. (2004). Roundabout I-VI. London Poems (2001-2003). Londres: Writers Forum. 